International Journal of Electrical Engineering and Technology (IJEET)

Volume 11, Issue 4, June 2020, pp. 241-245, Article ID: IJEET_11_04_027

Available online at https://iaeme.com/Home/issue/IJEET? Volume $=11 \&$ Issue $=4$

ISSN Print: 0976-6545 and ISSN Online: 0976-6553

DOI: https://doi.org/10.34218/IJEET.11.4.2020.027

\title{
SMART FARMING FIELD OBSERVATION USING EMBEDDED SYSTEMS
}

\author{
N Ashokkumar \\ Associate Professor, Department of Electronics and Communication Engineering, \\ Sree Vidyanikethan Engineering College, Tirupathi, India

\section{Krishnagandhi P} \\ Assistant Professor, Department of Electrical and Electronics Engineering, \\ Nandha Engineering College, Erode, India
}

\section{B Kannan}

Assistant Professor (Sr.Gr.), Department of Electronics and Communication Engineering, Ramco Institute of Technology, Rajapalayam, India

\section{Y David Solomon Raju}

Associate Professor, Department of Electronics and Communication Engineering, Holy Mary Institute of Technology \& Science, Hyderabad, India.

\begin{abstract}
Farming gives as one of the monetary strong establishment to most of the provincial India. Dominant part of the individuals in rustic spots set up their own homesteads for their job. The ordinary strategies that they use require a great deal of human work and devour vitality. There is no perfect water system strategy for every single climate condition, soil structures and assortment of yield societies. In view of absence of information in the progression of innovation, numerous multiple times they endure an incredible misfortune because of abrupt change in climate conditions, absence of gracefully of water or abundance flexibly of water just as the utilization of composts and deficient funding to purchase apparatus.

This research work proposes an embedded framework based farming field observing plan that create and execute the utilization of various sensors embedded to an AVR microcontroller. The sensors joined are temperature, soil moisture and rain detector sensors. In light of the state of the soil detected by the soil moisture sensor and the state of rain, it turns ON/OFF the siphon for flexibly of water to the field. $L C D$ is utilized to show the state of field gave by the different sensors. This framework is relied upon to permit the ranchers in assessing the soil conditions through which it can lessen the undesirable use of water and permitting appropriate yield of harvests just as decreasing human work.
\end{abstract}


Key words: AVR microcontroller, Temperature Sensor, LCD, Rain Detector Sensor and Soil Moisture Sensor.

Cite this Article: N Ashokkumar, Krishnagandhi P, B Kannan and Y David Solomon Raju, Smart Farming Field Observation Using Embedded Systems. International Journal of Electrical Engineering and Technology, 11(4), 2020, pp. 241-245. https://iaeme.com/Home/issue/IJEET?Volume=11\&Issue $=4$

\section{INTRODUCTION}

Farming which is considered as one of the prime control of person has $64 \%$ of the complete accessible land involved by farming out of which it expends $85 \%$ of accessible new water [1].The issues looked by the conventional instrumentation dependent on discrete and wired strategy has been fathomed through the usage of remote technique which gives an ease remote controlled water system arrangement and an ongoing perception of the field [2]. Numerous new thoughts are being taken up to permit farming mechanization to thrive and convey its maximum capacity. The prologue to this cutting edge innovation expends less time as well as permits the rancher to do his farming exercises all the more productively.

In this framework, all the gadgets deal with their own with the assistance of the sources of info got from the sensors [3]. The sensors which are put in the field give us the information with respect to the field which is then controlled and observing by programmable controller. The farming field observing server framework proposed in this work gathers the data, for example, temperature, soil moisture substance and identification of rain which influences the development of yields and soil arrangement through the sensors introduced outside. One of the main consideration targets controlling the undesirable use of water. The majority of the framework points keeping in see the instructive and money related foundation of the normal Indian ranchers [4]. Both nursery based too an open field can be considered for observing the field.

One of the significant variables to remember is keeping up the moistness and temperature which are incredibly affected by the outside environment. The nursery must be furnished with additional sensors and actuators for continuous observing and control [5]. The development of harvests in the nursery is mind boggling issue and along these lines it tends to be improved if an information is accessible which speaks to the measure of water, temperature, compost and so on required at that development. The life span, ripeness and improvement of harvests rely on microclimate [6]. The framework predominantly targets giving a modest, solid, cost effective and simple to utilize innovation which would help in transformation of assets, for example, water and in automat punch ranches [4], centers around investigating vitality proficient components to limit the vitality at different square levels, for example, the microcontroller, the conveying radio, and the sensors [7], foreseeing the beginning of germination of the ailment relying upon specific arrangement of temperature, soil moisture, and relative dampness which is a key factor for the debasement of the yield of harvest [8] and supplanting the wired conventional technique for watering[9] with a programmed framework in this manner moderating water and permitting appropriate development to the plants [10].

\section{EMBEDDED FARMING FIELD}

The framework comprises of an AVR microcontroller which is the core of the framework. Different sensors, for example, LM35 temperature, YL-69 soil moisture and raindrop detector sensors are utilized. A siphon is appended to a transfer which is then associated with the controller that siphons water contingent upon the water necessity by the soil and LCD for showing the state of the field. The code for the framework is created utilizing embedded $\mathrm{C}$ in 
AVR studio programming which can be additionally checked utilizing proteus programming and programming interface to the equipment utilizing avrubd.

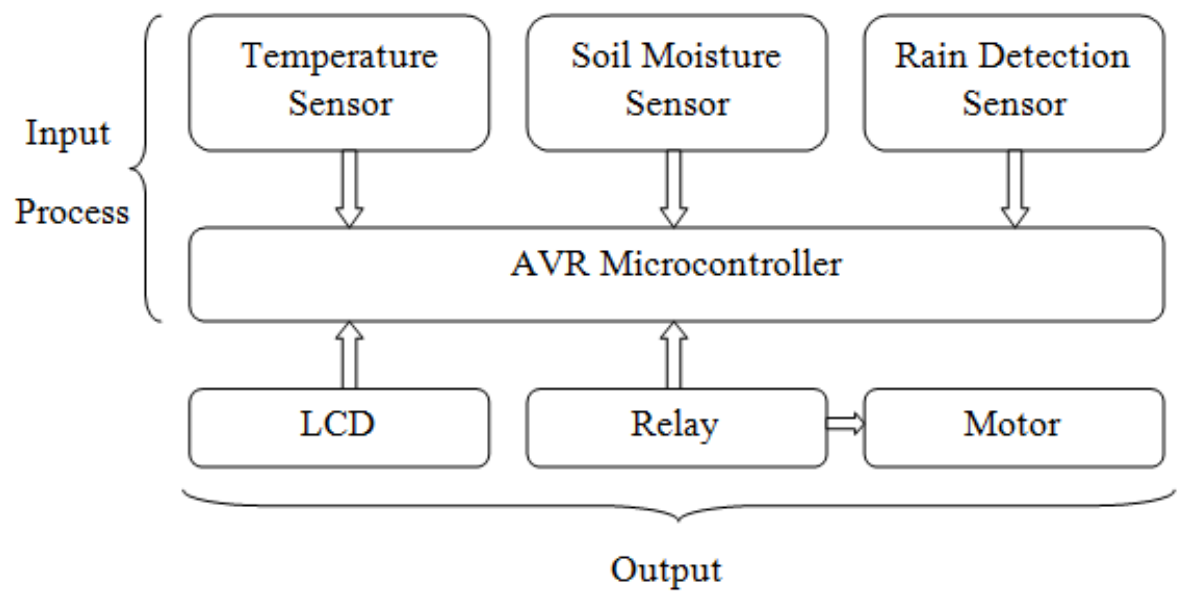

Figure 1 Farming Field System

\section{SENSORS CALIBRATION}

LM35 Temperature Sensor: Adjustment of LM35 temperature sensor has been performed under three temperature conditions: ordinary, hot and cold conditions. The sensor's working base is the voltage that read over the diode. Vin of $5 \mathrm{~V}$ has been set in the force flexibly and the yield readings were seen regarding $\mathrm{mV}$ through Vout. The general condition used to change over yield voltage to temperature is:

$$
\text { Temperature }\left({ }^{\circ} \mathrm{C}\right)=\text { Vout } *\left(100^{\circ} \mathrm{C} / \mathrm{V}\right)
$$

From the diagram, we can infer that the temperature rises at whatever point the voltage increments. The sensor records any voltage drop between the transistor base and producer. Along these lines the yield voltage changes directly with temperature.

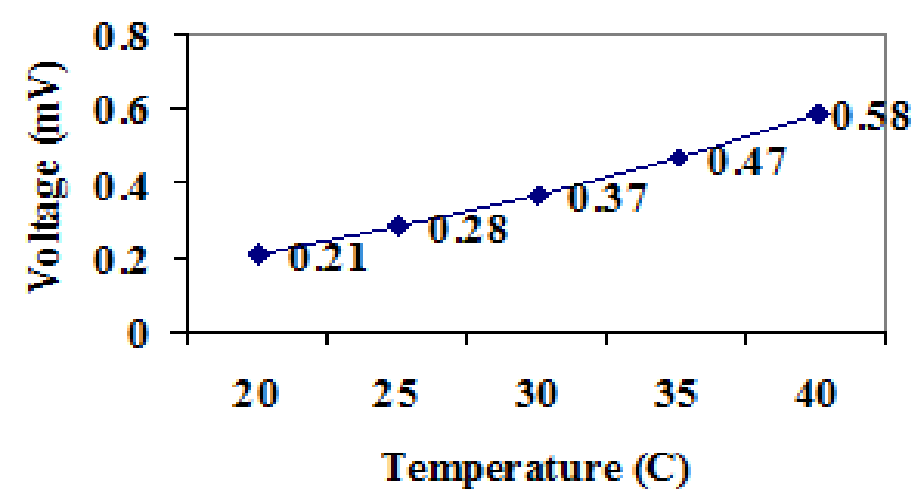

Figure 2 Temperature Sensitivity

Soil Moisture Sensor: Adjustment of YL-69 soil moisture sensor has been performed by setting the info voltage Vin $5 \mathrm{~V}$ and $90 \mathrm{~g}$ of soil kept in a glass receptacle. By including $20 \mathrm{ml}$ of water after each time span the accompanying readings were watched. 


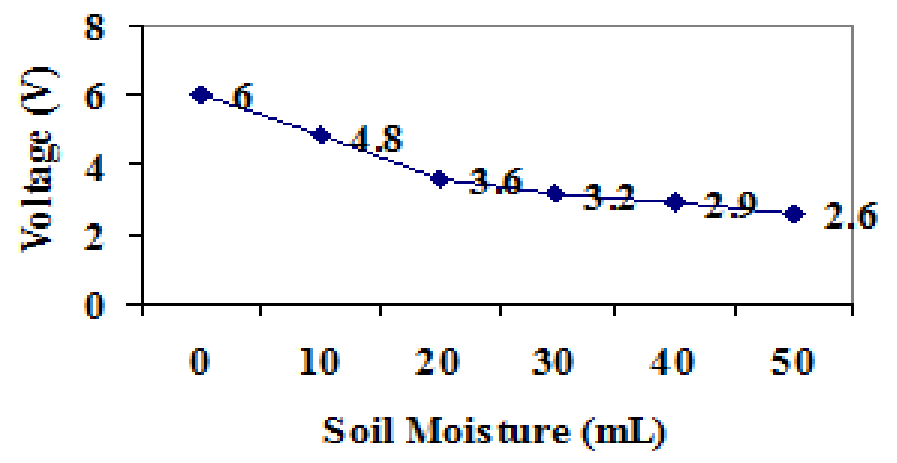

Figure 3 Soil Moisture Sensitivity

From the chart, we can see that as current is passed over the cathodes through the soil; the protection from the current in the soil decides the soil moisture. On the off chance that the soil has more water, opposition will be low and along these lines progressively momentum will go through. Then again when the soil moisture is low, the sensor module yields a significant level of obstruction.

Rain Detection Sensor: The adjustment of rain detector sensor has been finished by associating with a 7V gracefully and permitting the water to fall in droplets in the rain board sensor. From the diagram, we can infer that as the estimation of voltage diminishes, water force increments.

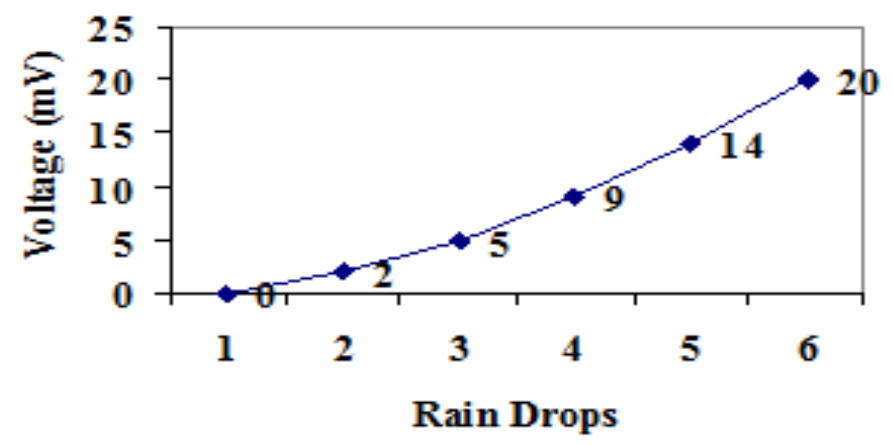

Figure 4 Rain Drops Sensitivity

\section{PERFORMANCE ANALYSIS}

At the point when the soil moisture is under $40 \%$, the sensor voltage is enhanced which is then given to the controller. Contingent upon the state of the rain from the raindrop sensor board, the voltage got is sufficient to drive and turn on the hand-off. LCD shows the outcomes as "MOTOR ON" or "MOTOR OFF" and "RAINY" or "DRY". Essentially, when the soil moisture is more prominent than $40 \%$, the voltage got isn't sufficient to drive and turn on the hand-off. Along these lines, during this condition the transfer is killed. Taking into account whether it rains or not, the siphon won't work in this condition as the soil moisture level is high. LCD shows the outcomes as "MOTOR OFF" and "RAINY" or "DRY".

Table 1 Performance Evaluation

\begin{tabular}{|c|c|c|}
\hline Condition of Soil & Condition of Rain Drop Sensor & Condition of Motor \\
\hline$>40 \%$ & "RAINY" & "MOTOR OFF" \\
\hline$>40 \%$ & "DRY" & "MOTOR OFF" \\
\hline$<40 \%$ & "RAINY" & "MOTOR OFF" \\
\hline$<40 \%$ & "DRY" & "MOTOR ON" \\
\hline
\end{tabular}




\section{CONCLUSION}

Embedded framework based observing of the field ends up being an ongoing input control framework which spreads up all the important prerequisites required for farming field observing framework. The model introduced prompts a commitment in modernizing the agrarian field framework where the framework is gotten in minimal effort and in dependable activity which can be introduced in urban remote places too, keeps from wastage of water in this way decreasing the physical work which is valuable for the ranchers and expanding yield of harvests. Moreover, more sensors can be included for appropriate observing of the field and establishment of correspondence frameworks to the client for giving the continuous state of the field as SMS just as MMS office for video catching of the field.

\section{REFERENCES}

[1] Pandchurang H. Tarange, Rajan G. Mevekari and Prashant A.Shinde (2015) "Web Based Automatic Irrigation System using wireless sensor network and Embedded Linux Board", 2015 International Conference on Circuit, Power and Computing Technologies (ICCPCT).

[2] S.G. Galande, G.H. Agrawal, (2013) "Embedded Controlled Drip Irrigation System", International Journal of Emerging Trends \& Technology in Computer Science, Volume 2, Issue 5, September - October, pp.37-41.

[3] Imtinungla, Samar Jyoti Saikia and Hemashree Bordoloi, (2017) "Embedded System based Agricultural Field Monitoring System", International Journal of Electronics Engineering Research, Volume 9, Issue 7, pp.977-984.

[4] Nandurkar, Sunita et al. (2014) "Design and development of precision agriculture system using wireless sensor network." 2014 First International Conference on Automation, Control, Energy and Systems (ACES), 1-6.

[5] G Ramprabu, S Sivakami, M Kanmani, (2019) "Performance Analysis of IoT based Smart Agriculture System", International Journal of Engineering and Advanced Technology, Volume 8, Issue 4, April, pp.1342-1344.

[6] A J Hake and A J Patil. (2014) Article: Condensation Control in Polyhouse using Embedded System. International Journal of Computer Applications 108(18):1-4.

[7] V. Singh, I. P. Singh and S. K. Sud, (2014) "Low power embedded controlled sensor network for agricultural applications," IEEE Long Island Systems, Applications and Technology (LISAT) Conference 2014, Farmingdale, NY, pp. 1-4, doi: 10.1109/LISAT.2014.6845222..

[8] Nilesh R. Patel, Swarup S. Mathurkar, Rahul B. Lanjewar and Ashwin A. Bhandekar, (2013) "Microcontroller based Drip Irrigation system using smart sensor", Annual IEEE India Conference (INDICON)

[9] Chetana A. Kestikar and Rutuja M. Bhavsar, (2012) "Automated Wireless Watering System (AWWS)", International Journal of Applied Information Systems (IJAIS), Volume 2, Issue 3.

[10] Mritunjay Ojha, Sheetal Mohite, Shraddha Kathole \& Diksha Tarware (2016) 'Microcontroller Based Automatic Plant Watering System' International Journal of Computer Science and Engineering (IJCSE) Vol. 5, Issue 3, Apr - May 2016; 25-36@ IASET. 